\title{
Relapsing polychondritis: bone marrow and circular fibrous nodules in the aorta
}

\author{
G E Wilson, P S Hasleton, J J Manns, J S Marks
}

\begin{abstract}
A case is reported of extensive aortic calcification, bone formation, and haemopoietic tissue in a woman with relapsing polychondritis. An additional feature was 'clock face' nodules of collagen in the aorta.
\end{abstract}

Relapsing polychrondritis is unusually diagnosed at necropsy. In particular, aortic manifestations are rare. We present a case where the entire aorta was affected by the disease and gave a histological pattern we have not seen previously.

\section{Case report}

A 40 year old housewife was seen in April 1960 with a history of episodic swelling of the face and tongue with conjunctivitis, which was associated with certain foods, suggesting angioneurotic oedema. She did not respond to antihistamines or hyposensitisation and no allergens were identified. In 1966 she had bilateral iridocyclitis, which responded to topical hydrocortisone. She also complained of deafness, tinnitus, and episodes of swollen and painful ears. Later, in 1966, the facial swelling recurred associated with weals on her neck, forearms, and hands. A collagen disease was suspected, and treatment was started with oral prednisolone.

Despite a good initial response to steroids she developed, in 1971, an episodic blistering itchy rash on the forehead, scalp, and flexor surfaces of the forearms and red pruritic papules over the abdomen. The rash lasted 24 to 72 hours and was worse if steroids were reduced to less than $10 \mathrm{mg} /$ day. The erythrocyte sedimentation rate was $120 \mathrm{~mm} / \mathrm{h}$. There were no lupus

Department of Pathology, Regional Cardiothoracic Centre, Wythenshawe Hospital, Manchester G E Wilson P S Hasleton

Department of Medicine, Regional Cardiothoracic Centre, Wythenshawe Hospital, Manchester J J Manns

Department of

Rheumatology, Stepping Hill Hospital, Stockport J S Marks

Correspondence to: Dr P S Hasleton, Regional Cardiothoracic Centre, Wythenshawe Hospital, Manchester M23 9LT. erythematosus cells and tests for antinuclear factor and sheep cell agglutination were also negative. Skin biopsy showed subepidermal bullae with an acute dermal inflammatory cell infiltrate, but no specific diagnosis was made.

In 1979 she had further attacks of conjunctivitis and marked scleral thinning. She complained of aching over the sternum, the muscles of the neck and shoulders with associated arm weakness. A blowing early diastolic murmur was heard along the left sternal edge, but there was no cardiomegaly. In 1983 she had a left sided hemiparesis, from which she made a good recovery. At this time she had pain and stiffness of the small joints of the hands and further painful swelling of the auricles of both ears. The erythrocyte sedimentation rate remained high at $107 \mathrm{~mm} / \mathrm{h}$. An electrocardiogram showed sinus tachycardia and left axis deviation. A chest $x$ ray showed aortic valve calcification extending into the proximal ascending aorta and cardiomegaly. There was no history of rheumatic fever or hypercalcaemia. (Calcium $2.44 \mathrm{mmol} / 1$, inorganic phosphate $1.03 \mathrm{mmol} / \mathrm{l}$, albumin $38 \mathrm{~g} / \mathrm{l}$ ).

Three years later she went into severe left ventricular failure with a collapsing pulse and a loud diastolic murmur along the left sternal edge. Cardiac catheterisation confirmed severe aortic incompetence. During this procedure she became bradycardic and died.

Treponema pallidum haemagglutination antibody test, Venereal Disease Research Laboratory antibody test, and fluorescent treponemal antibody test were persistently negative during the course of her disease.

\section{NECROPSY FINDINGS}

The main necropsy findings were in the heart and aorta. The heart and thoracic aorta together weighed $875 \mathrm{~g}$ (normal heart weight $300 \mathrm{~g}$ ). The right atrium was dilated and the tricuspid valve showed mucoid change. The right ventricle weighed $98 \mathrm{~g}$ (normal up to $65 \mathrm{~g}$ ) using the technique described by Fulton, Hutchinson, and Jones. ${ }^{1}$ The pulmonary and mitral valves were normal. The left atrium was dilated and the left ventricle weighed $269 \mathrm{~g}$ (normal up to $190 \mathrm{~g}$ ). The patient's three aortic valve cusps and aortic annulus were severely calcified. The ascending thoracic aorta was very heavily calcified (fig 1) and the wall was up to $1 \mathrm{~cm}$ thick. The descending thoracic and abdominal parts of the aorta were also abnormal showing severe patchy calcification. The walls of the common and internal carotid arteries were thickened. There was no evidence of atheroma in the aorta, coronary or cerebral arteries.

\section{MICROSCOPY}

The aortic valve was heavily calcified, containing bone and an associated lymphocytic infiltrate. The aorta at all levels was markedly abnormal. Extensive neovascularisation of the outer and middle third of the media was seen through most of the length. In most areas the inner third of the media was normal and well defined (fig 2). Many medial vessels were cuffed by lymphocytes. No evidence of vasculitis was seen either in the aorta or in any of the other tissues examined. There was a marked increase in medial fibrous tissue and extensive calcification. In some areas the collagen deposition was in the form of 'clock face' type nodules with peripherally orientated fibroblasts (fig 3 ).

Fragmentation of elastic fibres was present, 


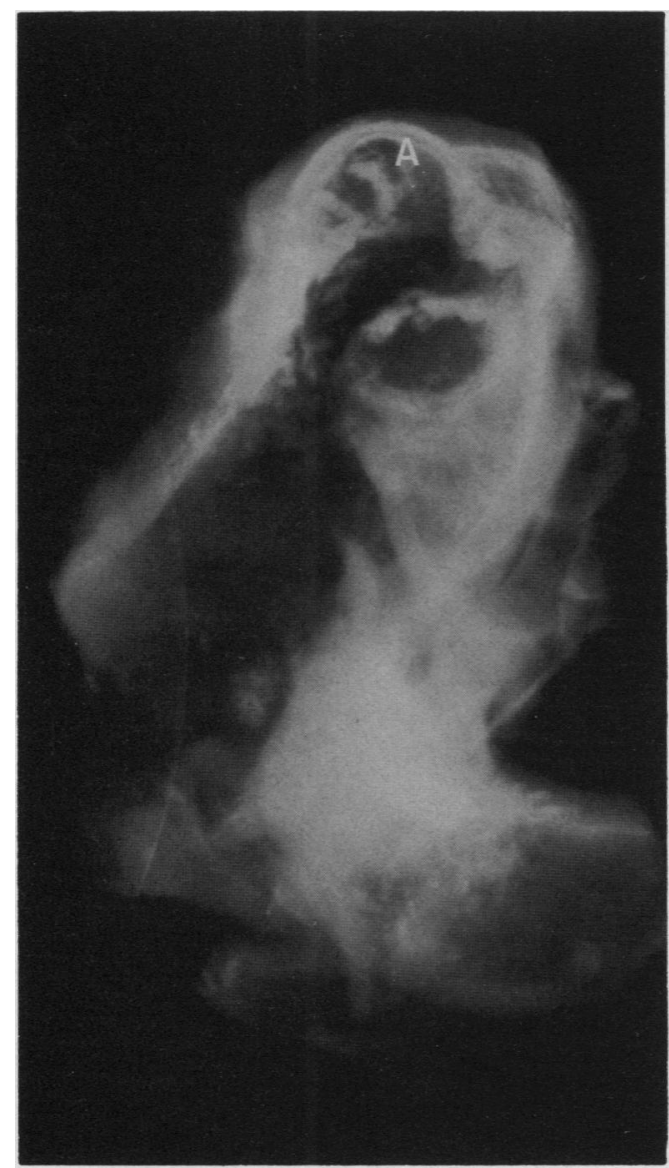

Figure 1 Radiograph of the thoracic aorta showing marked calcification. ( $A=$ aortic arch).

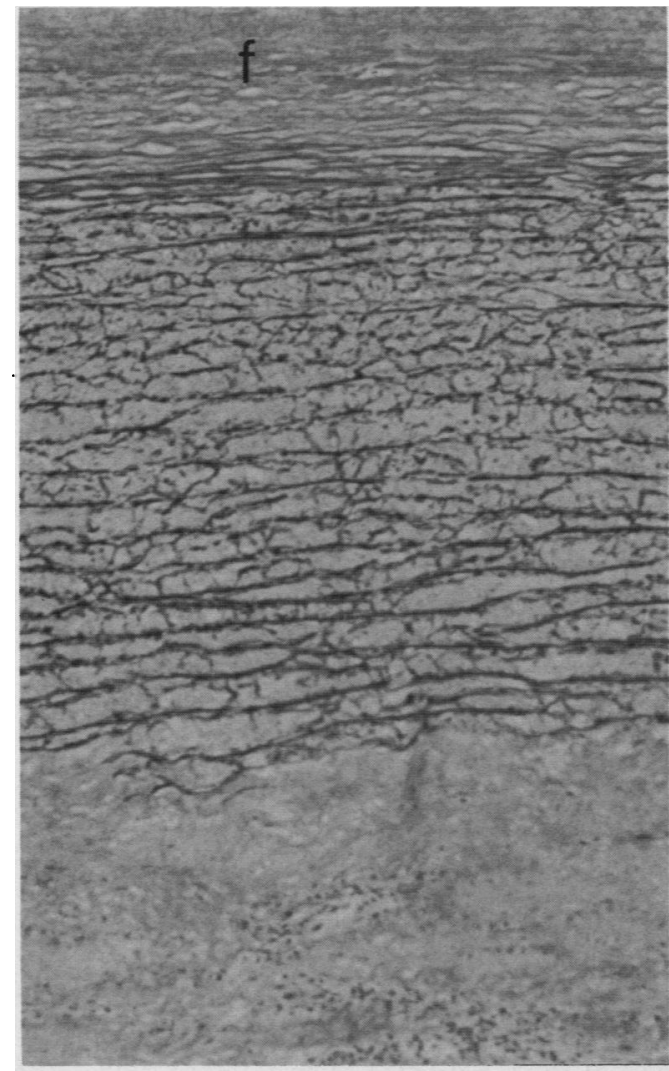

Figure 2 Normal inner third of the media. The lumen is obscured by intimal fibrosis $(f)$. (Elastic van Gieson.)

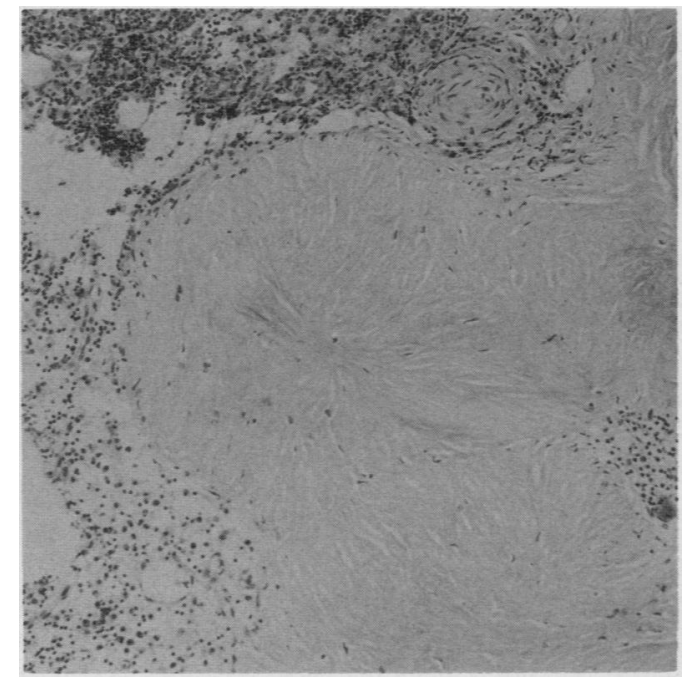

Figure 3 Collagen with a 'clock face' appearance along with bone marrow. (Haematoxylin and eosin.)

and in some areas little remaining elastic tissue was seen. Areas of mature bone containing haemopoietic marrow (fig 4) were present in the ascending, descending, and abdominal aorta. Medial neovascularisation and fibrosis was seen in the common and internal carotid arteries and the pulmonary trunk. The coronary arteries were histologically normal.

\section{Discussion}

We present a case of a woman with the probable diagnosis of relapsing polychondritis, in whom much of the aorta and aortic valve were severely calcified and also ossified. Our patient fulfilled the clinical criteria for relapsing polychondritis ${ }^{2}$ as she had episodic auricular chondritis, audiovestibular damage, conjunctivitis, iridocyclitis, scleromalacia, non-specific skin eruptions, myalgia, and flitting polyarthralgia.

The aorta was generally thickened by fibrous tissue, which was, in some areas, in the form of well defined 'clock face' type nodules of collagen. Such nodules have not to our knowledge been previously described in the aorta or any other organ. Extensive medial neovascularisation, elastin fragmentation, and calcification were seen and, most unusually, foci of mature bone containing hameopoietic marrow were present at all levels of the aorta. The disease process extended to the common and internal carotid arteries.

Abnormalities of the aortic valve and aorta have been previously described in patients with relapsing polychondritis. Pearson et al reported two cases with abnormalities of the aortic ring, and the initial $1.5 \mathrm{~cm}$ of the ascending aorta were greatly dilated. ${ }^{3}$ In the second case there was aneurysmal dilatation of the entire ascending aorta. Unlike our case, there was no intrinsic abnormality of the aortic valve cusps. Histologically they described medial fibrosis, neovascularisation, and chronic inflammation and emphasised the sparing of the inner part of media. Ascending aortic dilatation has been widely reported since; in one case it was 


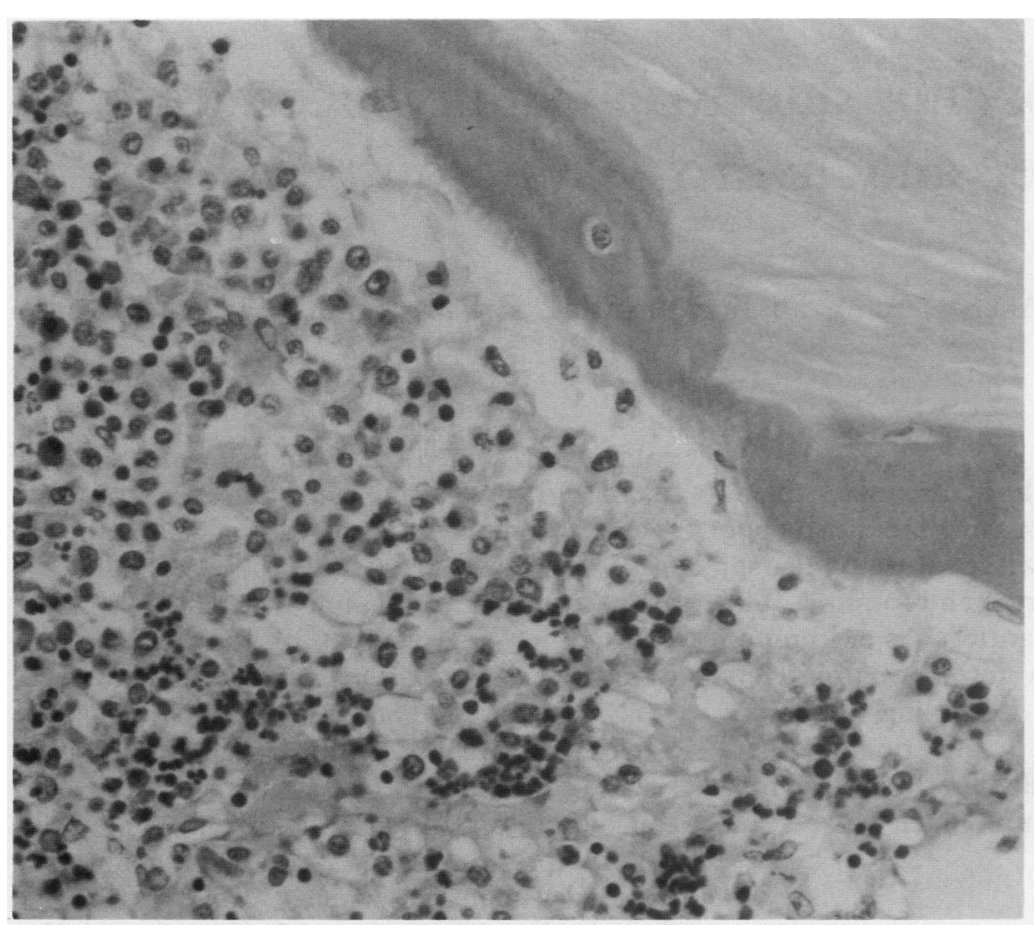

Figure 4 Area of bone formation (top right) with marrow containing megakaryocytes, in the aorta. (Haematoxylin and eosin.)

associated with an aortic arch syndrome. ${ }^{4}$ In another case aortic valve fibrosis and inflammation causing aortic regurgitation preceded abnormalities of the aortic root by four years. ${ }^{5} \mathrm{~A}$ dissecting aneurysm of the ascending aorta ${ }^{6}$ and multiple thoracic and abdominal aortic aneurysms have also been described. ${ }^{7}$ We have been unable to find reports of bone, marrow, or the classical arrangement of the collagen in the aorta.

The main differential histological diagnosis is syphilitic aortitis when the calcification is primarily intimal and there is an aortitis with endarteritis obliterans, usually complicated by atheroma. Calcification can occur in atherosclerosis but not with this underlying histology or distribution. Lupi, Horwitz, and Sanchez found radiographical evidence of thoracic aortic calcification in $19 \cdot 1 \%$ of patients with Takayasu's arteritis, ${ }^{8}$ but the ascending aorta is not usually affected.

1 Fulton R M, Hutchinson E C, Jones A M. Ventricular weight in cardiac hypertrophy. Br Heart $\mathcal{f}$ 1952; 14: 413.

2 McAdam L P, O'Hanlan M A, Bluestone R, et al. Relapsing polychondritis: prospective study of 23 patients and a polychondritis: prospective study of 23 patients and a review of

3 Pearson C M, Kroening R, Verity M A, Getzen J H. Aortic insufficiency and aortic aneurysm in relapsing polychondritis. Trans Assoc Am Physicians 1967; 80: 71-90.

4 Giordano M, Valentini G, Sodano A. Relapsing polychondritis with aortic arch aneurysm and aortic arch syndrome. Rheumatol Int 1984; 4: 191-3.

5 Sohi G S, Desai A M, Ward W W, Flowers M C. Aortic cusp involvement causing severe aortic regurgitation in a case of
relapsing polychondritis. Cathet Cardiovasc Diagn 1981; 7: 79-86.

6 Hainer J W, Hamilton G W. Aortic abnormalities in relapsing polychondritis: report of a case with dissecting aortic polychondritis: report of a case with dissecti

7 Cipriano P R, Alonso D R, Baltaxe H A, et al. Multiple aortic aneurysms in relapsing polychondritis. Am $\mathcal{F}$ Cardiol 1976;

8 Lupi H E, Horwitz S, Sanchez T G. Calcification in Takayasu's arteritis. Vascular Surgery 1973; 7: 259-64. 